\title{
Effect of UCS intensity on the acquisition and extinction of a one-way avoidance response'
}

\author{
K. E, MOYER AND JAMES H, KORN \\ CARNEGIE INSTITUTE OF TECHNOLOGY
}

Forty one female albino rats received 50 trials of acquisition training in a one-way avoidance task with IICS (shock) intensities of $0.5,1.5,2.5$, or $3.5 \mathrm{ma}$, and were subsequently extinguished. The 0.5 ma group made significantly fewer avoidance responses and had longer response latencies in acquisition and on the first extinction trial. The highest shock level produced significantly longer escape latencies on early trials but did not retard avoidance learning. These results are compared with those found using other avoidance tasks.

A previous experiment (Moyer \& Korn, 1964) has shown that relatively intense shock interferes with the acquisition of both escape and avoidance responses in a shuttle-box situation. The present experiment was conducted in order to determine whether the same relationship between learning and UCS intensity would hold in the considerably simpler one-way avoidance task.

Method

The Ss were 41 naive female albino rats from the Carnegie Tech colony which were 60-80 days of age at the start of the experiment.

The apparatus was the same as the one used in the previous study with the following modifications. End partitions were removed which increased the box length to $34-1 / 2$ in. and a $6 \times 5 \times 8$ in. goal box was added to one end with a goal box opening of $2-3 / 4 \times 4-3 / 4$ in. The lights over the box were increased to 25 watts and both lights were on at all times. No tone was used. The shock device was the same one used in the previous study. The shock intensities used for the four groups in this experiment were: Group I $(\mathrm{N}=9), 0.5 \mathrm{ma}$; Group II $(\mathrm{N}=11), 1.5 \mathrm{ma}$; Group III $(\mathrm{N}=11), 2.5 \mathrm{ma}$; Group IV $(\mathrm{N}=10), 3.5 \mathrm{ma}$.

At the beginning of a trial the $S$ was placed in the end of the box away from the goal and facing away from the goal. After 5 sec. the appropriate shock level was automatically applied to the grid floor. After the $\mathrm{S}$ escaped into the goal box the latency was recorded, the $S$ was removed from the goal box and placed again in the avoidance box for the next trial. The intertrial interval was $25 \mathrm{sec}$. Fifty trials were given on Day 1 and extinction trials were given on Day 2. The extinction procedure was the same as the learning procedure except that no shock was used. An animal was considered extinguished when it gave a latency of $20 \mathrm{sec}$.

If, during learning, an S gave 5 latencies of $300 \mathrm{sec}$. it was considered to be a non-learner and the data was not used in the computation of results. Two Ss in the 0.5 group and one $S$ in the 2.5 group met the non-learning criterion.

The mean percentage of avoidance responses over all 50 acquisition trials for each of the groups was: $0.5-38.4 ; 1.5-66.2 ; 2.5-70.5 ; 3.5-71.6$. Analysis of variance showed that the group means differed significantly $(\mathrm{F}=6.62, \mathrm{df}=3 / 37, \mathrm{p}<.01)$.

The mean response latencies in blocks of five trials are plotted in Fig. 1. Again the effect of US intensity was significant $(F=3.30, d f=3 / 37, p<.05)$, as was the Trial Blocks effect $(F=8.18, d f=9 / 333, p<.001)$, and the Intensity by Trial Blocks interaction $(F=2.03$, $\mathrm{df}=27 / 333, \mathrm{p}<.05)$. The interaction effect was due primarily to the larger means for the 0.5 and $3.5 \mathrm{ma}$ groups on the first block of trials. Individual comparisons using $t$-tests were made between the group means on Trial Block 1: 0.5 vs. $1.5, t=17.09 ; 0.5$ vs. $2.5, t=17.33 ; 0.5$ vs. $3.5, t=12.94 ; 1.5$ vs. $3.5, t=3.95$; 2.5 vs. $3.5, t=4.20$. In all cases $d f=37, p<.01$. The difference between the 1.5 and 2.5 groups was not significant $(t<1.00)$.

The mean number of trials to the first avoidance response for each of the groups was: $0.5-19.7 ; 1.5-$

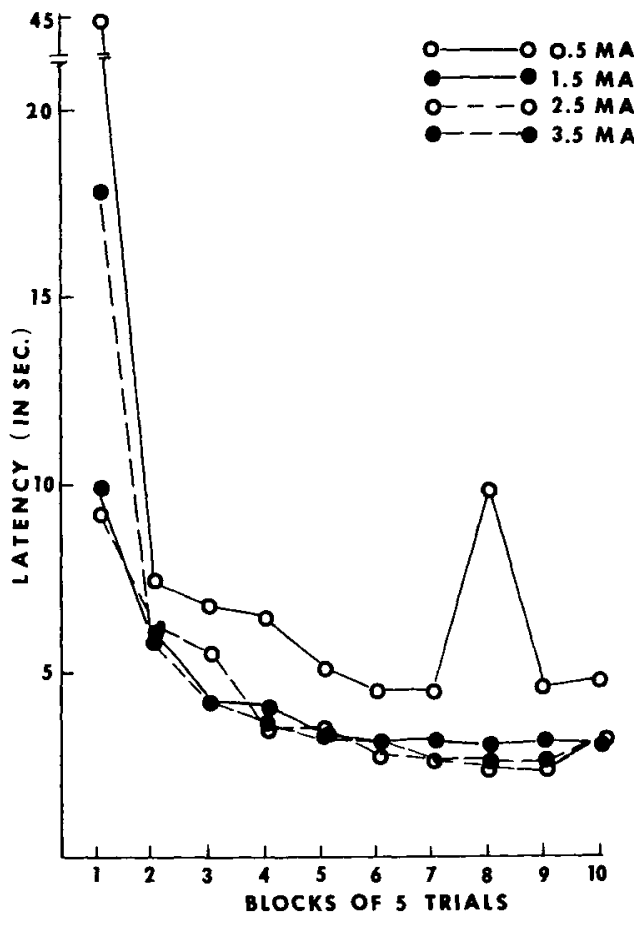

Fig. 1. Escape and avoidance latencies in blocks of five trials. 
$11.5 ; 2.5-7.2 ;$ and $3.5-8.2$. Analysis of variance showed that the group means differed significantly $(F=3.30$, $\mathrm{df}=3 / 37 . \mathrm{p}<.05$ )

The median number of trials to criterion in extinction for the four groups (from 0.5 to $3.5 \mathrm{ma}$ ) was 1.2, $2.5,2.3$, and 4.0 . The hypothesis of significant group differences was supported by a Kruskal-Wallis test $(\mathrm{H}=13.43, \mathrm{df}=3, \mathrm{p}<.01)$ although Mann-Whitney tests revealed only one significant comparison: 0.5 vs.

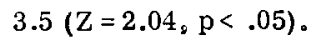

The median latency on the first extinction trial for the 4 groups (from 0.5 to $3.5 \mathrm{ma}$ ) was 19.5, 7.4, 13.1, 4.9 sec. Again, the Kruskal-Wallis test was significant $(H=9.47, \mathrm{df}=3, \mathrm{p}<.05)$. Individual comparisons showed the 0.5 group to differ significantly from the other three groups: $1.5(\mathrm{U}=24, \mathrm{p}<.10)$, $2.5(U=18, p<.02), 3.5(U=18, p<.05)$. None of the other comparisons was significant.

These results indicate that the $\mathrm{Ss}$ in the lowest shock group did learn the avoidance response, although that shock level clearly is not optimal. With per cent avoidance, number of trials to first avoidance during acquisition, or latency of first extinction trial used as a criterion, the 0.5 group is significantly inferior to the other groups. The relatively intense shock levels of 2.5 and $3.5 \mathrm{ma}$ do not interfere with the acquisition of one-way avoidance as they do with the more complex shuttle avoidance. However, as Fig. 1 shows, the 3.5 ma level does interfere with the escape response. The latency for the first five trials is significantly longer for that group than for the 1.5 and 2.5 ma groups.

In spite of the fact that the high shock level interferes with escape, the acquisition of the avoidance response is not retarded as is shown by the number of trials to the first avoidance response. Thus, disruption of the escape response alone is probably not sufficient to account for the fact that higher shock intensities retarded avoidance acquisition in the shuttle box situation as Moyer \& Korn (1964) suggested. Theios \& Lynch (1965) who also failed to find that high shock interfered with one-way avoidance, hypthesize that the $S$ learns to avoid the location where it has been previously shocked and this learning is a function of shock intensity. Thus, in the shuttle box, the Ss tendency to stay where it is constitutes a competing response which interferes with the acquisition of shuttle avoidance. They further indicate that in situations such as one-way avoidance and instrumental avoidance, where such a competing response is not learned, the higher shock intensities will not interfere with learning. This position is also probably not the whole answer since D'Amato (1965) has shown that high shock intensities do interfere with discriminated bar-press avoidance learning.

The ultimate explanation for the fact that an intense UCS interferes with complex avoidance learning may well involve a number of factors including the "staying response" suggested by Theios \& Lynch (1965), the "conditioned response suppression" suggested by D'Amato (1965) and the escape disruption suggested by Moyer \& Korn (1964).

\section{Reterences}

D'Amato, M. R. Discriminated lever-press avoidance learning as a function of type and intensity of shock. J. comp. physiol. Psychol., in press.

Moyer, K. E., \& Kom, J. H. Effect of UCS intensity on the acquisition and extinction of an avoidance response. J. exp. Psychol., $1964,67,352-359$.

Theios, J., \& Lynch, A. Differential effects of shock intensity on one-way and shuttle avoidance conditioning. Report No. 8 of Conditioning Research Laboratory, Department of Psychology, University of Texas, 1965 .

\section{Note}

1. This investigation was supported in part by a research grant M-1298 from the National Institutes of Health, United States Public Health Service to K. E. Moyer. The authors are grateful to Paul Mottey who served as a laboratory technician for this experiment. 